\title{
Eu, tu e ele: fragmentação e redescoberta de uma identidade para muito além do corpo
}

\section{Andrea Pereira Moraes \\ Doutoranda em Literatura Brasileira-Programa de Pós-Graduação em Letras e Linguística da Universidade Federal de Alagoas}

RESUMO: Esse texto analisa o romance Muito além do corpo, de Luzilá Gonçalves Ferreira, procurando desvelar os caminhos de sua escrita sob a perspectiva da teoria feminista. O olhar lançado sobre o romance nos revela uma escrita que busca recompor a história das mulheres, em um processo em que identidades são desconstruidas e novas possibilidades apontadas. Permite-nos uma reflexão sobre a literatura como espaço de subversāo dos valores impostos pela sociedade patriarcal.

Palavras-chave: Luzilá Gonçalves Ferreira; literatura de autoria feminina; escrita e identidade
ABSTRACT: This text analyzes Luzilá Gonçalves Ferreira's novel Muito Além do Corpo, in order to disclose its writing strategies from the perspective of the feminist theory. The look upon the novel reveals a writing mode that searches to revise women's history in a process in which identities are deconstructed and new possibilities pointed out. It evokes a reflection on literature as space of subversion of the values imposed by patriarchal society.

Keywors Luzilá Gonçalves Ferreira; women's literature; writing and identity 
Este ensaio tem como objetivo analisar o romance Muito além do corpo, de Luzilá Gonçalves Ferreira. No entanto, pretendo tecer, inicialmente, um breve comentário acerca da literatura de autoria feminina em geral, principalmente, daquelas autoras que se inscrevem no contemporâneo.

Evidentemente, não é de hoje que as mulheres escrevem e essa escrita vem se desenvolvendo desde os séculos passados, apesar de todos os empecilhos sociais impostos à figura feminina. Entretanto, não se pode deixar de levar em conta que somente a partir do século XX os textos escritos por mulheres avançam na sociedade, sendo o movimento feminista um ponto propulsor fundamental para esse avanço. Afirmamos isso, visto que o movimento feminista surge com o objetivo de desvelar as práticas patriarcais da sociedade, procurando enfatizar, em um primeiro momento, a identidade/homogeneidade entre homens e mulheres.

Posteriormente, com o avanço da luta feminista, e com a inserção da mulher na universidade, o movimento busca resgatar a categoria da diferença como mediadora das relações de gênero (não como processo de inferioridade, mas de heterogeneidade). Isso significa afirmar que há uma mudança substancial no sentido, pois há um deslocamento e uma ressignificação dos conceitos de sexo e gênero.

$\mathrm{Na}$ atualidade, a ideia de igualdade é substituída pela de diferença. A partir disso, o ponto de vista defendido é que as experiências entre homens e mulheres, e mais, entre as próprias mulheres, efetivamente, são diferentes e que dessa forma devem ser percebidas, respeitadas e estudadas. É importante a diferenciação entre desigualdade e diferença. Homens e mulheres não são desiguais, apenas diferentes. Como consequências, surgem os mais diversos estudos sobre a questão da identidade da mulher.

Joan Scott (1988), uma das teóricas mais importantes do feminismo, aponta que uma das relações 
mais produtivas de nosso tempo é a de feminismo com o pós-estruturalismo. É essa relação que produz as discussões acerca do deslocamento dos sentidos:

Encontrei uma nova maneira de analisar as construções de significado e as relaçōes de poder, que questionava as categorias unitárias e universais, e tornava históricos conceitos que normalmente são tratados como naturais (como "homem" e "mulher") ou como absolutos (como a igualdade ou a justiça). Além disso, o que mais me aíraía era a conexão histórica entre os dois movimentos. O pósestruturalismo e o feminismo contemporâneo são movimentos de fins do século XX, que compartilham uma certa relação crítica autoconsciente diante das tradições política e filosófica estabelecidas. Portanto, parecia valioso, para as feministas acadêmicas, explorar essa relação visando seus próprios fins. (SCOTT, 1988, p.203)

Para Scott, a teoria pós-estruturalista responde aos seus requerimentos, ou seja, ela nada mais é que uma teoria útil e relevante para a prática política, ou pelo menos algumas de suas categorias centrais, que a autora denomina de "termos úteis do pós-estruturalismo, apropriados pelas feministas: linguagem, discurso, diferença e desconstrução" (p.204). Evidentemente, sua posição não é a única acerca do tema, mas é uma prática que domina, na atualidade, a teoria feminista. Essa questão será representada e refletida, não somente na teoria acerca da cultura, mas também na teoria literária e na própria literatura produzida por mulheres em nosso tempo.

Todo esse movimento traz em seu bojo o questionamento dos valores sociais impostos às mulheres, dando início a toda uma produção acadêmica, política e literária para a desconstrução dos estereótipos e dos conceitos que permearam a identidade feminina. $O$ desenvolvimento, relativamente rápido, desse processo vai 
desencadear no movimento que hoje é conhecido como pós-modernidade, assinalado, principalmente, entre as décadas de 70 e 80 .

Uma das premissas desse movimento em geral, e particularmente do movimento feminista, é a construção de novos valores para a produção e análise dos textos escritos por mulheres, visto que, durante toda a história, os valores determinados pela e para a sociedade eram marcadamente masculinos, heterossexuais e brancos, velados pela ideologia moderna que proferia os discursos sobre igualdade e liberdade. Esses questionamentos fizeram emergir várias discussões sobre o cotidiano da mulher e as possibilidades de ultrapassá-lo, seja através dos movimentos políticos efetivos, seja através da literatura.

Dessa forma configura-se um jogo dialético em que as mulheres buscam a transformação objetiva da realidade, através de ações políticas; assim como essas transformações são refletidas pela literatura de autoria feminina. Em prefácio à obra de Helena parente Cunha, As doze cores do vermelho, Schmidt (1998) resume esta questão:

Um dos eixos paradigmáticos que alicerçam as formações culturais e práticas da modernidade e, portanto, ponto convergente da crítica pós-moderna é o conceito essencialista de identidade universal do Homem, preconizada pelo discurso humanista, o qual remete a um sujeito coeso, centrado e masculino, investido de positividade e, por isso mesmo, elevado à condição de sujeito normativo da cultura. (SCHMIDT, 1998, p.07)

A autora coloca que a literatura de autoria feminina, na contemporaneidade, com o objetivo de desarticular o conceito essencialista de identidade do sujeito, põe em questão não só a centralidade da identidade, mas principalmente da "autoridade política, social e simbólica" ainda presente nos dias atuais. 
É no cerne desse momento histórico que se encontra inserida a literatura de autoria feminina mais incisiva e emblemática, em defesa de uma escrita baseada nas discussões sobre as identidades da mulher e seu lugar na sociedade. Inscrevendo-se neste período e encampando esta luta, o romance de Luzilá Gonçalves Ferreira não poderia se configurar de forma diferenciada. Essa constatação poderá ser observada, como veremos a seguir, a partir da análise crítica de Muito além do corpo.

Muito além do corpode Luzilá Gonçalves Ferreira é um romance produzido e publicado na década de 80 , exatamente no período em que as escritoras cada vez mais procuravam falar de si mesmas e de outras mulheres, buscando construir identidades e desmistificar mitos e estereótipos. Em entrevista concedida à Izabel Brandão, a autora do romance qualifica a escrita de autoria feminina:

A escrita é um exercício pois de autoreconhecimento e de conhecimento do mundo, uma aventura individual e política. Toda vez que uma mulher escreve, consequentemente contribui para um melhor conhecimento das mulheres, no modo como se investe no texto - e o texto literário é um investimento profundo do ser, o maior certamente. $(24 / 01 / 2002)$

Esta fala nos revela que não só os romances de autoria feminina discorrem sobre a experiência da mulher, mas principalmente, as produções literárias de Luzilá Gonçalves nos contam uma história que ao mesmo tempo é sua e do outro. Não significa que a narrativa de Muito além do corpo pretenda essencializar uma identidade, mas sim desvelar e construir novas possibilidades identitárias.

O romance em análise é composto por seis partes, divididas entre três pessoas EU, TU e ELE, narrado por uma única personagem: uma mulher fragmentada entre dois amores. Encontramos nisso o primeiro diferencial da obra de Luzilá, posto que os personagens são referidos a partir 
de pronomes pessoais substituindo os nomes (que ao configurar-se indicariam uma identidade). Há uma relação direta com o leitor/receptor, que pode se identificar com qualquer personagem: é a possibilidade da auto-reflexão através da escrita, encontrada explicitamente no romance:

E agora eu faço um livro. E dele também me espanto, construção de palavras e pedaço de vida, objeto que não existia antes de mim e que vai fazer seu caminho, em mim e fora de mim, em outros talvez, um livro é um mistério, parte da gente que se vai buscar por estradas insabidas, que constrói apesar da gente, e é espanto como o é um filho: de onde me veio a força de inserir no mundo algo tão meu e tão alheio a mim? Tão meu e tão outro, eu e o outro, eu e as outras, exercício de mergulho em mim mesma. $\left(\mathrm{MAC}^{1}, 1988, \mathrm{p} .31\right)$

A autora, ao recorrer à metatextualidade, não só afirma que o ato de escrever é um exercício de autoconstrução, como também uma possibilidade de construção do outro. O objetivo da narrativa fica assim explícito através da forma, ou seja, não só pretende resgatar identidades, mas construí-las através do romance. Evidentemente, Luzilá Ferreira discute as possibilidades da escrita e de sua representação enquanto processo de auto e alter conhecimento. Conforme Magalhães (2002):

A arte constitui uma expressão privilegiada da subjetividade; o resultado do reflexo artístico e sua recepção são possibilidades concretas de afirmação da personalidade, pois significam o ato de escolha que um sujeito - o artista, ou receptor - realiza sobre a forma de tratar os conflitos, que estão diretamente ligados à auto-construção humana. (MAGALHÃES, 2002, p.70)
'MAC, abreviação de Muito Além do Corpo. 
O romance Muito Além do Corpo reflete o cotidiano de uma mulher, com o explícito intuito de questionar a história das mulheres e contribuir, através da escrita, com possíveis soluções para este conflito. Nesse sentido, a personagem-narradora traduz uma busca do ser, de um ser que se auto-constrói, partindo de sua própria história. Para isso, Luzilá Ferreira desreferencializa a personagem do instituído "lugar-comum" da mulher, ou seja, esta mulher não está caracterizada como mãe, esposa ou filha, já não se deixa dominar pelo dito na sociedade.

Aos 40 anos de idade, a personagem é uma mulher independente, que possui dinheiro, "um teto todo seu" (para utilizar as palavras de Virgínia Woolf) e a liberdade necessária para operar escolhas e transformações. No entanto, a personagem remonta um processo de maturação e reconciliação com sua história e a história das mulheres, perpassando pelo passado, presente e apontando possibilidades futuras:

Sou várias, mutável, tecido formado de diversas fibras, desde o mais leve algodão natural e rústico, aos fios sofisticados e inquebráveis, transparentes, quase invisíveis. Entre uns e outros, todas as nuances, mulher é coisa complexa, incompleta, felizmente. Sempre a se fazer. (MAC, 1988, p.27)

Para percorrer este caminho, a personagemnarradora parte do que para ela é o princípio da vida: o amor. Somente o amor pode ultrapassar o corpo, ir "muito além do corpo", do visível e do tangível. A personagem lança o olhar em três dimensões, para TU - o ser amado; para EU - a busca de si mesma; e para ELE - outro ser amado. Encontramos, nesse diálogo amoroso, um dos pontos de transgressão narrativa, pois se trata de uma mulher fragmentada entre dois homens, sem culpa e sem medo.

O TU representa o ser amado, a quem a personagem dedicara 10 anos de sua vida, em pleno 
relacionamento de trocas amorosas, mas este configurase em um outro construído sob o olhar da personagemnarradora. Um espelho do outro, formando o Nós:
Amigos sim, companheiros de travessia, irremediavelmente cúmplices: assim éramos nós, aqueles anos todos. Eu e Tu, por toda a vida, Eu e Tu que ninguém poderia imaginar senão como um bloco, fortalezas fechadas a terceiros, estátua talhada numa só pedra, vagarosamente talhada ao correr do tempo, sem data prevista de conclusão. (MAC, 1988, p.10)

$\mathrm{O}$ amor efetivamente estava presente, entretanto encontramos implícita a ideia dominante do inseparável, do inconfundível. Aqui a noção do indissociável, em que um mais um tornam apenas um, não há individualidade. Nesse momento, a personagem idealiza a relação e o ser amado, representando o discurso corrente na sociedade, em que os homens racionalizam e as mulheres idealizam:

E havia também: regiões por onde navegavas e eras tão distinto daquele que gostarias de ser. Então não mais eras Tu e sim um Ele, que possuía contigo leve parentesco. Um ele escorregadio, capaz de jogar com as palavras, fazê-las dizer o contrário do que atestavam os acontecimentos. Aqueles momentos eu também te parecia dupla: a amada espontânea e aberta, que te mostrara caminhos claros onde te expandias vestido de luz e com olhos claros. Mas também: obstáculo à liberdade Dele, que se queria descomprometido com coisas e pessoas, liberado da necessidade de falar, de se dizer, se justificar. (MAC, 1988, p.22)

A personagem-narradora, a partir do momento que narra e/ou escreve seu romance com TU, vai adquirindo consciência de sua posição no relacionamento, por isso 
trata de buscar em sua própria história a origem desses sentimentos. Na história do Eu, há um retorno ao passado, para compreender melhor o presente:

Também não sei em que espelho ficou perdida minha outra face, Cecília. Um dia desses me olhei: passei diante do espelho, vi-me de relance. E me interessaram: aqueles olhos me olhando, a mulher me encarando hostil, com uma frieza de que não me julgara capaz. Talvez seja apenas astigmatismo, eu me disse, essa dureza, esse jeito de encarar. Como poderia ser minha inimiga? (MAC, 1988, p.26)

Nesse breve diálogo com Cecília Meireles e seu poema "Espelho", a personagem cobra a si mesmo, num processo de auto-reflexão, o reconhecimento de sua individualidade, de sua pessoalidade, não como reflexo do outro, mas como de si mesma. Durante toda a história da sociedade, a mulher foi coagida a identificar-se com o outro (o homem), impedida de olhar a si como sujeito agente, com experiência diferenciada dos homens; agora há uma cobrança de reconciliação da própria mulher com a experiência feminina, determinada por processo de identidade e diferença, ou seja, a luta de todas as mulheres pela diversidade e heterogeneidade.

Luzilá constrói a personagem para desvelar o quanto a ideologia patriarcal cumpriu o seu objetivo, mas que é possível sua percepção e desconstrução, afirmando: "E eu: meu rosto lavado. E apesar disso, cercada de rapazes, companhia aliás que sempre preferi à das colegas, meninas falando futilidades. Foram preciso anos para me reconciliar com as da minha raça" (MAC, 1988, p.27).

A preocupação em entender o processo no qual as mulheres estão inseridas, deve ser considerada como um processo de procura de individualidade e identidade, há muito tempo velada pela sociedade sexista. Nesse sentido, Ataíde (1999) corrobora esta afirmação, posto que: 
A individualidade do ser, principalmente do ser feminino, não se marca pelo sentimento, pelo amar um homem, pelo fechar-se e entregar-se - como enclausura o pensamento burguês. É, antes, no entender o todo e no entender-se, garantindo sua participação na sociabilidade. (ATAÍDE, 1999, p.98)

Essa afirmação potencializa-se na atitude da personagem que, antes de falar no outro ser amado e retornar a falar do TU, refaz seu caminho no sentido de reencontrar-se longe da companhia masculina. Esse reencontrar-se só é possível no passado, visto que este ser amado não pode mais ser apagado de sua vida, mas ela pode inverter esse processo de dependência, reconceituando o amor; o amor que move a vida, mas não supera a morte, nem a dor, nem o sofrimento, por isso mesmo "o limitado poder do amor." (MAC, 1988, p.37). $\mathrm{O}$ amor vem acompanhado de tudo que a vida oferece: alegrias e tristezas. No entanto, a forma de encará-la é que vai determinar suas ações e atitudes. A personagem descobre que é agente de milagres e da sua própria história:

Mas talvez naquele dia, a futura mulher aprendeu na menina que a gente pode ser agente de milagres. Milagre: tudo aquilo que pode vir a ser. Nunca se sabe do que se é capaz, nem como um simples e impensado gesto pode pôr em movimento as forças obscuras da vida. (MAC, 1988, p.51)

Esse discurso é apresentado já no término da narrativa do EU, o que remete ao próximo capítulo ELE, que pode ser relacionado com "simples e impensado gesto que pode pôr em movimento as forças obscuras da vida." Por isso mesmo, o outro que penetra a vida da personagem surge também com o objetivo de destituir certas visões tradicionais de relacionamento, desconstruir o ponto de vista imposto pela sociedade: 
$\mathrm{O}$ que durante meses me desarvorou. Todas as minhas idéias sobre o amor, sobre mim, eram postas em questão, eu tendo de revisar as familiares e aceitas habituais noções de fidelidade, exclusividade, ciúmes. E, despojando-me do preconcebido e decidido pelos outros, antes mesmo que eu existisse, cheguei a me encontrar única e irrepetível, mulher com quem principia a história. (MAC, 1988, p.25)

Essa é uma nova identidade que a personagem se permitira descobrir e que fora velado pelo posto e pelo dito, mas a subversão se configurou, quando ela mesma pôde principiar uma história (ou tornar-se consciente dela), diante de sua própria percepção de vida. $\bigcirc$ que antes era Nós, com o TU amado, rompe e a noção de individualidade é retomada, não como sentimento de culpa, mas sim de liberdade. Não é mais a possibilidade do uno, e sim do fragmentário e múltiplo: a soma das diferenças. No entanto, a ruptura já havia se feito, o TU não correspondia às diferenças e eles já não eram mais os mesmos: "E talvez então nos pudesse ter sido poupada a experiência de ruptura que logo vivemos, e que veio pôr em questão o próprio modo como a gente se relacionava" (MAC, 1988, p.59).

O novo relacionamento rompe com velhos conceitos e padrões; novo também é o homem com quem a personagem se envolve. Se o corpo é metáfora de nós mesmos, Luzilá introduz o novo em todos sentidos, viaja do corpo jovem até o momento de nova realidade, que se converterá numa nova subjetividade: o amor por si mesma:

Eu voltava aos quinze anos e ele era meu primeiro amor, com toda a indizível alegria que havia experimentado então, quando me sentira de súbito um adulto, participando de uma comunidade de gente grande, que ama e é amada não apenas pelos pais e irmãos. Meu primeiro amor e a certeza de que eu existia e era amada por mim mesma. (MAC, 1988, p.64) 
A personagem-narradora passa por uma transformação ao longo da narrativa, acumulando experiências possíveis, entre amores (inclusive o amor próprio). Entretanto, o ser amado que transformou e transmudou a vida da personagem, tornando-se também em um TU já não existia, a morte (que o amor não supera) o levara, mas ele já tinha deixado marcas na vida dela: "Mas hoje só por mim falarei, só por mim e para mim. E perdoa: se o silêncio não é minha resposta a esse teu forçado silêncio, tu que não podes responder, nem me dizer eu te amo, tu do outro lado" (MAC, 1988, p.73).

Apesar da dor e do sofrimento pela perda dos dois amores - um pela separação, outro pela morte - a personagem não perde a perspectiva de sua vida, retoma mais um capítulo dedicado a ela mesma, em que recobra seu passado mais vez, afirmando: "Fiquei quieta este tempo todo"(p.74) e é preciso agora gritar, falar de si, falar das mulheres, sem referir-se a mais ninguém. Numa bela escrita, quase poética, resume sua busca:

Estar só, e a partir desta solidão me reconstruir: só assim posso me apresentar aos outros. Então direi: voltei e sou assim, a gente sempre volta. Mas queria voltar inteira, os pedaços tão colados que nem se veriam os remendos. (MAC 1988, p.75)

Neste mesmo trecho, a narradora nos aponta que "a gente sempre volta", ligando-se ao retorno ao outro, visto que a humanidade e o amor estão intimamente ligados, mas esta volta não pode ser alheada do mundo e de si mesma, deve ser consciente das necessidades de cada um. Por fim, retorna ao primeiro ser amado, também amadurecido.

Vale ressaltar que o retorno que a personagem faz ao primeiro TU amado não é recaída, ou falta, posto que esta perpassou toda a narrativa buscando construir um sentido para si mesma. Ao contrário, é uma volta com novas possibilidades: um futuro potencial com o 
outro, e não sozinha. Ao final, reafirma seu amor, mas não se arrepende de suas experiências, é o outro que tem que se desculpar:

- Queria teu perdão, falaste.

- Te amo, respondi. (MAC 1988, p.79)

O romance de Luzilá Gonçalves Ferreira, notoriamente, buscou romper com todos os estereótipos inculcados à figura feminina, desde o casamento e a maternidade até o estar amando a dois homens igualmente, sem culpa, nem medo. Muito além do corpo é uma viagem ao desconhecido, aquilo que vai em nossas mentes (como Penélope o fez) e que há muito tempo não foi permitido expor. Luzilá Ferreira e sua personagem-narradora percorrem este caminho desvelando as possibilidades de um novo reencontro, a mulher consciente de si e de suas necessidades, tendo apenas a si mesma como espelho, não mais o outro.

A proposta da autora é o ir além da superficialidade, do velado, do dito e do exposto, para descortinar as inúmeras possibilidades que a mulher pode alcançar, ultrapassando toda a ideologia sexista e todo sentimento de culpa; é a mulher que pode amar o outro, consciente de seus limites e sem pedir licença, nem desculpas. 


\section{Referências}

ATAÍDE, Vicente. Amor e ideologia em Jorge Amado. Revista Literatura e Sociedade, n.4. Maceió: Edufal, 1999.

FUNCK, Suzana Bornéo (org.). Trocando idéias sobre a mulher e a literatura. Florianópolis: Universidade de Santa Catarina, 1994.

FERREIRA, Luzilá Gonçalves. Muito além do corpo. São Paulo: Scipione, 1988.

MAGALHÃES, Belmira. História e representação literária: um caminho percorrido. In Revista Brasileira de Literatura Comparada, n.6, 2002.

SCHMIDT, Rita Terezinha. Prefácio. In: CUNHA, Helena Parente. As doze cores do vermelho. 2 ed. Rio de Janeiro: Tempo Brasileiro, 1998.

SCOTT, Joan. Igualdade versus diferença: os usos da teoria pósestruturalista. In: Debate feminista: cidadania e feminismo. São Paulo, 1999. 